\title{
Frequency of Hypoglycemia in Severe Malaria in Children Aged 5 To 144 Months In Kinshasa
}

Muziazia Lupemba Jacques $^{*}{ }^{*}, 2$, Fei Guan ${ }^{1}$, Mercy Julian Mwamunyi ${ }^{3}$, Jiahui Lei ${ }^{1}$

${ }^{1}$ Department of Parasitology, School of Basic Medicine, Tongji Medical College, Huazhong University of

Science and Technology, Wuhan 43003, China;

${ }^{2}$ Kikimi hospital, Democratic Republic of Congo, street Ngampani.

${ }^{3}$ Department of Nephrology, Union Hospital, Huazhong University of Science \& Technology, Jiefang Road 1277, Wuhan, Hubei, 430022, P.R.China

*Address correspondence to Muziazia Lupemba Jacques, Department of Parasitology, School of Pathogen Biology, Tongji Medical College, Huazhong University of Science and Technology, Wuhan 43003, China;

\begin{abstract}
Background

Hypoglycemia is an important complication of severe malaria, especially in children and pregnant women. In 2017 Kikimi hospital changed quinine treatment policy from $15 \mathrm{mg} / \mathrm{kg}$ loading (plus $10 \mathrm{mg} / \mathrm{kg} 12$ hourly) to $20 \mathrm{mg} / \mathrm{kg}$ loading (plus $10 \mathrm{mg} / \mathrm{kg} 8$-hourly) to comply with new WHO guidelines. This presented us with the opportunity to examine whether there was any dose relationship of quinine and hypoglycemia occurrence, in particular, in severe malaria in children from 5 to 144 months.

\section{Methods}

The study was retrospective of children aged 5 to 144 months admitted to KIkimi hospital with severe malaria between April 2017 and July 2018, before and after the introduction of the new quinine treatment regimen by the WHO. The patient's blood glucose at four hours was measured until intravenous quinine was stopped. Clinical events immediately before or simultaneously with each episode of hypoglycemia (glucose $<=3.0 \mathrm{mmol} / \mathrm{l}$ ) were recorded.
\end{abstract}

\section{Results}

Age group at high parasitemia was 13 to 48 months and165 children received the old quinine diet and 125 the new diet. We found no evidence of an increase in the prevalence of hypoglycemia $(<=3.0 \mathrm{mmol} / \mathrm{L})$ with the new regimen compared with the old one $(15 \%$ versus $15 \%)$; similar results were noted for deep hypoglycaemia $(<2.2 \mathrm{mmol} / \mathrm{L}) 9 \% \mathrm{v} 6 \%, \mathrm{p}=0.09$. The episodes coincided with the indicators of the severity of the disease: coma (55\%), circulatory insufficiency (36\%) and respiratory distress (19\%), but less frequently with convulsions (11).

\section{Conclusion}

With a single case of malaria falciparum infection with high parasitemia in children aged 13 to 48 months. There was no evidence to indicate a dose relationship between quinine and the occurrence of hypoglycemia. Hypoglycemia was associated with disruption of glucose perfusion and transfusion. Close monitoring of blood glucose should be targeted during complications in children who remain seriously ill.

Keywords: Children, Severe Malaria, Hypoglycemia, Quinine.

\section{Background}

Hypoglycemia is a life-threatening complication of falciparum malaria infection [1]. The pathophysiology of this treatable complication is controversial with both the parasite and quinine therapy implicated. The hypoglycemia evolved before quinine administration and resolved as the parasitemia was successfully 
eradicated [2,3]. Hypoglycemia is an important complication of severe P. falciparum malaria, especially in children and pregnant women. The prevalence of hypoglycemia appears to vary in different parts of the world and in different age groups ranging from 8\% in SE Asian adults [4] to 10-20\% in African children [56]. Hypoglycaemia in children is independently associated with poor outcome [7-8] and increased mortality [2,9-11] predominantly when accompanied by acidaemia $(\mathrm{pH}<7.3)$ or hyperlactataemia (lactate $>5$ mmol/l) [12,13]. The study was conducted on children aged from 5 to 144 months based on quinine dependence dose and the occurrence of hypoglycemia. In 2017, Kikimi Hospital adopted the new World Health Organization (WHO) guidelines for the treatment of severe falciparum malaria with quinine, recommending a loading dose of $20 \mathrm{mg} / \mathrm{kg}$ quinine followed by $10 \mathrm{mg} / \mathrm{kg}$ every hour [14]. Since 1998, the treatment of severe malaria depended on a loading dose of $15 \mathrm{mg} / \mathrm{kg}$, followed by $10 \mathrm{mg} / \mathrm{kg}$ twice daily. The objective of this study was to: allowed us to investigate whether there was a dose relationship between the presence of quinine and hypoglycemia, particularly in severe malaria in children from 5 to 144 months of age with either plan. We studied the clinical events and factors temporally associated with the development of hypoglycemia during admission.

\section{Epidemiology of malaria}

Knowledge of the technical aspects of malaria is needed to decide how to develop an appropriate malaria control strategy at the local level. Such familiarity can help to determine whether malaria can pose a significant risk to public health in a given situation, how widespread it is, which drugs would be effective and which would probably not, and which groups of the population is displaced. May be at increased risk of malaria and therefore require special attention. The overall level of immunity to malaria is highest in areas where malaria transmission is the most intense. The first exposure to malaria occurs very early in childhood, and with repeated exposures, the likelihood of severe illness or death lessens. In Africa, where the majority of malaria-associated deaths occur, the highest mortality rates occur in children less than 5 years old. It has been estimated that in the Democratic Republic of the Congo, malaria accounts for 30 percent of all deaths among children less than 5 years old. Malaria-associated mortality decreases rapidly with increasing age [15]. In areas with very high levels of transmission, severe malaria tends to manifest itself more frequently as anemia than as a cerebral disease. As transmission intensity decreases and population immunity is lessened, illness is seen more frequently in all age groups, and the incidence of cerebral disease increases relative to severe anemia.

Displaced populations coming from areas of little or no malaria transmission to areas with intense transmission are therefore at the highest risk of severe illness and death due to a lack of acquired immunity. Until they receive a protective level of protection to malaria, these populations will probably require a much more intensive intervention effort to achieve and maintain low rates of morbidity and mortality.

Malaria also has significant effects in the way of chronic or repeated infections, including anemia (especially among individuals with underlying malnutrition), and poor pregnancy outcomes. Anemia, itself a significant cause of mortality associated with malaria, is also a common reason for blood transfusion [16]

\section{Clinical}

Hypoglycemia is associated with a b prognosis $n$ severe malaria, but this does not necessarily mean that it is the cause of death. Treating or preventing hypoglycemia alone may not reduce mortality. However, until the path physiology is fully understood, this seems a reasonable aim [17].

\section{Methods}

Studies included a retrospective analysis of the two groups of children ( 5 to 144 months) confirmed by the severe malaria laboratory admitted to Kikimi Hospital in the Democratic Republic of the Congo. All children admitted to the hospital are examined to identify those with severe symptoms of malaria who are rapidly transferred after stabilization in the supervision unit. Case reports of selected children meeting strictly defined criteria for severe malaria ( $P$. falciparum parasitemia and altered consciousness and respiratory distress) were examined for this study. 165 children treated with the pre-quinine regimen (intravenous loading dose of $15 \mathrm{mg} / \mathrm{kg}$ and maintenance dose of $10 \mathrm{mg} / \mathrm{kg}$ every 12 hours) diluted in 5\% dextrose and infused intravenously hours and 125 children treated with the new quinine regimen recommended by the WHO (intravenous loading dose of $20 \mathrm{mg} / \mathrm{kg}$ and maintenance dose of $10 \mathrm{mg} / \mathrm{kg}$ 
every 8 hours) diluted in 5-fold dextrose. $\%$ and infused intravenously for 4 hours. The quinine used in both methods was obtained from a single supplier (Indus Pharma Ltd, LACOMEDA), with their respective certificates of analysis for each lot. This study does not include children admitted to the general ward with malaria parasitemia, which deteriorated after admission, meeting the definition of severe malaria. Parenteral and intravenous medications have been prescribed until the child can take and maintain fluids and oral medications. The oral anti-malarial drugs prescribed depended on the national treatment policy in effect at the time and included sulfadoxine-pyrimethamine or artemether-lumefantrine. On admission, blood glucose was measured in the laboratory using an automated glucose oxidase system. Then, the blood glucose was checked regularly using the monitoring device, one hour after admission, and four hours after cessation of quinine. Hypoglycemia, defined as either $3 \mathrm{mmol}$ or less, was managed by an intravenous bolus of $5 \mathrm{ml} / \mathrm{kg}$ of $10 \%$ dextrose, which is the standard treatment. Additional measures were taken during epileptic seizures or posture, transfusion, or clinical deterioration. The Accu-Chek TM machine was calibrated weekly, and every time a new box of test strips was opened. We also examined the frequency of hypoglycemia cases for three different definition thresholds; <2.2 mmol / 1 (severe hypoglycaemia), <2.5 mmol / 1 (moderate hypoglycaemia) and $<=3 \mathrm{mmol} / 1$ (possible hypoglycaemia). In clinical practice, different blood glucose thresholds are used to define hypoglycemia.

\section{Statistical analysis}

The proportions were compared for the qualitative variables using chi-square tests and Fisher's exact method if any. Malaria parasitemia was summarized as a geometric mean [95\% reference range]. For continuous variables, the Student's t-test was used to compare the mean differences between the two patterns. In all cases of non-normal data, the Mann Whitney test (Wilcoxon Rank sum test) was used to establish a comparison between the two groups. Clinical definitions of severity characteristics and our definition of circulatory collapse (hypovolemic shock ) were previously described [18, 19]. Variables with $\mathrm{p} \leq 0.15$ were chosen to be included in the multivariate logistic regression to account for confounding factors. Variables were adjusted for age in the multiple regression analysis. The regression model was tested for specification error and quality of fit. The significance has been evaluated at 5\%. The analysis was performed using State version 11 (State Corporation, Texas, and the USA).

\section{Result}

A total of 165 children were treated with the old dosing regimen (April 2017 to September 2017) and 125 children with the new dosing regimen (July 2018 - November 2018). Girls accounted for 50\% of the cases in both regimens. The median age children treated was 36 months (IQR 25 - 49) p <0.01. Table 1 presents parasitemia as a function of age, severe malaria anemia, and Table 2 presents the detailed characteristics of children's admissions from two regimens. Children with the schema of 2017 and 2018 had a higher parasitemia but a lower proportion of severity indicators (coma, deep breathing, and hypoglycemia) but with a higher severity indicator of severe anemia $(\mathrm{p}=0,01)$ (Table 2). Severe hypoglycemia $(<2.2 \mathrm{mmol} / \mathrm{L})$ was also more common at admission in both 2017 and 2018: $118(12 \%)$ compared to $89(9 \%)(\mathrm{p}=0.009)$, respectively.

Table 1. distribution of parasitemic children and severe malaria anemia

\begin{tabular}{|c|l|l|l|l|l|l|}
\hline Parasitemia & \multicolumn{3}{|c|}{ malaria } & \multicolumn{3}{c|}{ Severe malaria anemia } \\
\hline & aOR & {$[\mathbf{9 5 \%}$ CI $]$} & P & aOR & {$[\mathbf{9 5 \%}$ CI $]$} & P \\
\hline 0 & 1.35 & {$[1.09-2-26]$} & $<0.001$ & 1.00 & & \\
\hline$[0-1000]$ & 1.65 & {$[1.22-2.44]$} & $<0.001$ & 1.35 & {$[0.90-2.09]$} & NS \\
\hline$[1000-10000]$ & 2.21 & {$[1.69-2.82]$} & $<0.001$ & 2.65 & {$[2,08-3.28]$} & $<0.001$ \\
\hline$[10000-100000]$ & 2.08 & {$[1.66-2.62]$} & $<0.001$ & 2.52 & {$[2.06-3.12]$} & $<0.001$ \\
\hline$[100000-$ & 2.75 & {$[1.85-3.92]$} & $<0.001$ & 2.80 & {$[2.02-3.85]$} & $<0.001$ \\
$250000]$ & & & & & & \\
\hline$\geq 250000$ & 3.56 & {$[2.48-4.90]$} & $<0.001$ & 4.96 & {$[3.75-6.60]$} & $<0.001$ \\
\hline
\end{tabular}

The risk of developing malaria was associated with age (OR $=2.90,95 \%$ CI: 2.4-3.3, $\mathrm{p}<0.01)$ (Table 1). The proportion of parasitaemic children was higher in cases of severe malaria, respectively (38\%). Overall, 
$80 \%$ (79/290) of children with severe malaria anemia and hypoglycemia were between 13 and 48 months of age.

Table 2. Admission characteristics for children

\begin{tabular}{|c|c|c|c|}
\hline Clinical feature & Quinine 15mg/kg (n=165) & Quinine15mg/kg(n=125) & $\begin{array}{l}\text { P- } \\
\text { value }\end{array}$ \\
\hline Coma $(\mathrm{BCS} \leq 2)$ & $123 / 164(42)$ & $90 / 123(38)$ & 0.69 \\
\hline $\begin{array}{l}\text { Severe anaemia }(\mathrm{Hb} \\
<5 \mathrm{~g} / \mathrm{dl})\end{array}$ & $129 / 164(24)$ & $87 / 121(17)$ & 0.001 \\
\hline $\begin{array}{l}\text { Temperature } \\
\text { gradient }\end{array}$ & $263 / 161(28)$ & $55 / 122(20)$ & 0.001 \\
\hline $\begin{array}{l}\text { Hypoglycaemia }<= \\
3 \mathrm{mmol} / \mathrm{l}\end{array}$ & 155/164 (16) & $86 / 124(9)$ & 0.007 \\
\hline $\begin{array}{l}\text { Severe } \\
\text { hypoglycaemia }(< \\
2.2 \mathrm{mmol} / \mathrm{l})\end{array}$ & $119 / 163(12)$ & $89 / 123$ & 0.001 \\
\hline $\begin{array}{l}\text { Creatinine }>80 \\
\mathrm{mmol} / \mathrm{l}\end{array}$ & $125 / 164(25)$ & $94 / 124(21)$ & 0.68 \\
\hline $\begin{array}{l}\text { Potassium }>5 \\
\mathrm{mmol} / \mathrm{l}\end{array}$ & 149/164 (16) & $117 / 124(7)$ & $<0.01$ \\
\hline \multicolumn{4}{|l|}{$\begin{array}{l}\text { Mean laboratory } \\
\text { variable }[S D]\end{array}$} \\
\hline $\begin{array}{l}\text { Hemoglobin level, } \\
\mathrm{mg} / \mathrm{dl}\end{array}$ & $7.10[2.62]$ & $7.51(2.42)$ & 0.001 \\
\hline $\mathrm{PH}$ & $7.30(0.18)$ & $7.34(0.55)$ & 0.44 \\
\hline $\mathrm{PCO} 2, \mathrm{mmol} / \mathrm{L}$ & $4.25(1.90)$ & $3.97(1.74)$ & 0.18 \\
\hline $\begin{array}{ll}\text { Base } & \text { Deficit, } \\
\mathrm{mmol} / \mathrm{L} & \end{array}$ & $8.88(6.64)$ & $7.49(5.74)$ & 0.006 \\
\hline $\begin{array}{ll}\begin{array}{l}\text { Sodium } \\
\mathrm{mmol} / \mathrm{l}\end{array} & \text { level, }\end{array}$ & $135(5.64)$ & $134(5.55)$ & 0.05 \\
\hline $\begin{array}{l}\text { Creatinine level, } \\
\mathrm{mmol} / \mathrm{l}\end{array}$ & $66.89(42.8)$ & $64.79(33.64)$ & 0.52 \\
\hline
\end{tabular}

Presents the detailed characteristics of children's admissions from two methods. Children in 2017-2018 had a lower proportion of severity indicators (coma, deep breathing, severe anemia, and hypoglycemia) but a reliable temperature indicator.

Table 3. Timing and distribution of hypoglycemia

\begin{tabular}{|c|c|c|c|c|}
\hline & \multicolumn{2}{|c|}{ 2017: Quinine $15 \mathrm{mg} / \mathrm{kg}$ regimen } & \multicolumn{2}{|c|}{ 2018: Quinine $20 \mathrm{mg} / \mathrm{kg}$ regimen } \\
\hline Time period & $\begin{array}{l}\text { Frequency by } \\
\text { first episode } \\
(n=95) n(\%)\end{array}$ & $\begin{array}{l}\text { Frequency by } \\
\text { all episodes (n } \\
=70) n(\%)\end{array}$ & $\begin{array}{l}\text { Frequency by } \\
\text { first episode }(\mathrm{n} \\
=42) \mathrm{n}(\%)\end{array}$ & $\begin{array}{l}\text { Frequency by } \\
\text { all episodes (n } \\
=83) \\
\mathrm{n}(\%)\end{array}$ \\
\hline $0-24 \mathrm{Hrs}$ & $79(81)$ & $57(69)$ & $31(71)$ & $48(55)$ \\
\hline After 24 hrs & $20(13)$ & $39(18)$ & $40(18)$ & $20(24)$ \\
\hline After 48 hrs & $9(6)$ & $30(14)$ & $8(14)$ & $19(21)$ \\
\hline
\end{tabular}

The distribution and chronology of episodes of hypoglycemia were explored, and the results are presented. We found no statistical difference in the chronology of events between the two methods. 


\section{Discussion}

Despite some recent and localized successes in disease control, severe malaria remains a major public health burden in sub-Saharan Africa, killing over half a million children each year [20]. Parenteral quinine is. Therefore, one of the most widely used treatments in African hospitals and information about the potential iatrogenic side effects remain pertinent. Our study provides valuable information for clinicians treating children with severe malaria in Africa concerning the occurrence of life-threatening hypoglycemia and its clinical associations. Hypoglycemia occurs in $18 \%$ of children following admission, with over $70 \%$ of episodes occurring within 24 hours of admission. We found no evidence of a dose-response relationship between quinine and any degree of hypoglycemia after admission. The most important clinical variables at admission that predicted the development of hypoglycemia after admission were hypoglycemia, severe anemia, and temperature gradient (a marker of impaired perfusion or circulatory failure). Most episodes were single events and frequently concurrent with one or more markers of disease severity including coma, clinical features of impaired perfusion, deep breathing but less commonly associated with the time-honored suspected clinical associations of seizures or posturing. We found a coincidence of hypoglycemic episodes during transfusions or periods of disruption of intravenous glucose infusion. Overall, a fatal outcome was

more common in children developing hypoglycemia after admission.

\section{Noted}

In this study in DR Congo, we observed hypoglycemia following admission in the initially hypoglycemic children treated with quinine under intravenous infusion of $15 \mathrm{mg} / \mathrm{kg}$ and maintenance of $10 \mathrm{mg} / \mathrm{kg}$ in every 24 hours. Simple clinical features did not allow for reliable identification of these at-risk children. Therefore, if resources are very limited, it may be reasonable to limit blood glucose monitoring to children admitted for hypoglycemia, while ensuring that children are unable to drink a glucose infusion. Patient monitoring devices are sufficiently sensitive for clinical reasons. Such devices should not cause morbidity, and such devices should not be used for research purposes.

\section{Conclusions}

We found no relationship between the dose of quinine and the frequency or severity of hypoglycemia in DR.Congo children with severe malaria. In general, high parasitemia in children aged 13 to 48 months was $18 \%$ with hypoglycemia after the day of admission. Hypoglycemia was associated with disruption of glucose perfusion and transfusion. Due to the adverse outcome, a $25 \%$ mortality rate vs. $10 \%$ in patients with hypoglycemia indicates the need for close monitoring of blood glucose levels to be targeted during complications in children who remain critically ill.
Abbreviations
DR.Congo: the Democratic Republic of the Congo
OR: Odds ration
CI: Confidence Interval

\section{Conflict of Interest}

All authors declare no conflict of interest.

\section{Funding}

This work was supported by grants from the national natural sciences foundation of China (81571255) and grant from the ministry of science and technology China (2016YFC1305800).

\section{Ethical Approval:}

This work was carried out according to and by approval of ethical comity of China Tongji Medical College and Ministry of Health of DR of Congo.

\section{References}

[1] Krishna S, Waller DW, ter Kuile F, Kwiatkowski D, Crawley J, Craddock CF, Nosten F, Chapman D, Brewster D, Holloway PA. et al.( 1994)Lactic acidosis and hypoglycemia in children with severe 
malaria: pathophysiological and prognostic significance. Trans R Soc Trop Med Hyg. 88(1):67-73. doi: 10.1016/0035-9203(94)90504-5.

[2] White NJ, Warrell DA, Chanthavanich P, Looareesuwan S, Warrell MJ, Krishna S, Williamson DH, Turner RC.( 1983) Severe hypoglycemia and hyperinsulinemia in falciparum malaria. N Engl J Med.;309(2):61-66. doi: 10.1056/NEJM198307143090201.

[3] Maitland K, Levin M, English M, Mithwani S, Peshu N, Marsh K, Newton CR. Severe P. falciparum malaria in Kenyan children:( 2003) evidence for hypovolaemia. Qjm.; 96(6):427-434. doi: 10.1093/qjmed/hcg077.

[4] Achoki R, Opiyo N, English M.( 2009) Mini-review: Management of Hypoglycaemia in Children Aged 0-59 Months. J Trop Pediatr.

[5] Pidcoke HF, Wade CE, Mann EA, Salinas J, Cohee BM, Holcomb JB, Wolf SE.( 2010) Anemia causes hypoglycemia in intensive care unit patients due to error in single-channel glucometers: methods of reducing patient risk. Crit Care Med.; 38(2):471-476. doi: 10.1097/CCM.0b013e3181bc826f.

[6] J. Goljan, W. L. Nahorski, A. Wroczyńska, I. Felczak-Korzybska, and H. Pietkiewicz,( 2006) "Severe malaria - analysis of prognostic symptoms and signs in 169 patients treated in Gdynia in 1991-2005," International Maritime Health, vol. 57, no. 1-4, pp. 149-162,

[7] Taylor TE, Molyneux ME, Wirima JJ, Fletcher KA, Morris K.( 1988) Blood glucose levels in Malawian children before and during the administration of intravenous quinine for severe falciparum malaria. N Engl J Med.; 319(16):1040-1047. doi: 10.1056/NEJM198810203191602.

[8] Krishna S, Waller DW, ter Kuile F, Kwiatkowski D, Crawley J, Craddock CF, Nosten F, Chapman D, Brewster D, Holloway PA. et al. (1994) Lactic acidosis and hypoglycaemia in children with severe malaria: pathophysiological and prognostic significance. Trans $\mathrm{R}$ Soc Trop Med Hyg.;88(1):67-73. doi: 10.1016/0035-9203(94)90504-5.

[9] English M, Wale S, Binns G, Mwangi I, Sauerwein H, Marsh K(1998). Hypoglycaemia on and after admission in Kenyan children with severe malaria. Q J Med. 1998;91(3):191-197

[10] Marsh K, Forster D, Waruiru C, Mwangi I, Winstanley M, Marsh V, Newton C, Winstanley P, Warn P, Peshu N. et al.( 1995)Indicators of life-threatening malaria in African children. N Engl J Med.; 332(21):1399-1404. doi: 10.1056/NEJM199505253322102

[11] Holding PA, Stevenson J, Peshu N, Marsh K.( 1999) Cognitive sequelae of severe malaria with impaired consciousness. Trans R Soc Trop Med Hyg. 1999;93(5):529-534. doi: 10.1016/S00359203(99)90368-1.

[12] Idro R, Jenkins NE, Newton CR.( 2005) Pathogenesis, clinical features, and neurological outcome of cerebral malaria. Lancet neurology.;4(12):827-840. doi: 10.1016/S1474-4422(05)70247-7.

[13] Schellenberg D, Menendez C, Kahigwa E, Font F, Galindo C, Acosta C, Schellenberg JA, Aponte JJ, Kimario J, Urassa H. et al. (1999)African children with malaria in an area of intense Plasmodium falciparum transmission: features on admission to the hospital and risk factors for death. Am J Trop Med Hyg.; 61(3):431-438.

[14] Waller D, Krishna S, Crawley J, Miller K, Nosten F, Chapman D, ter Kuile FO, Craddock C, Berry C, Holloway PA. et al. (1995)Clinical features and outcome of severe malaria in Gambian children. Clin Infect Dis.; 21(3):577-587.

[15] Kawo NG, Msengi AE, Swai AB, Chuwa LM, Alberti KG, McLarty DG.( 1990) Specificity of hypoglycaemia for cerebral malaria in children. Lancet. 336(8713):454-457. doi: 10.1016/01406736(90)92009-7.

[16] Krishna S, Waller DW, ter Kuile F, Kwiatkowski D, Crawley J, Craddock CF, Nosten F, Chapman D, Brewster D, Holloway PA. et al. (1994) Lactic acidosis and hypoglycaemia in children with severe malaria: pathophysiological and prognostic significance. Trans R Soc Trop Med Hyg.; 88(1):67-73. doi: 10.1016/0035-9203(94)90504-5.

[17] Maitland K, Levin M, English M, Mithwani S, Peshu N, Marsh K, Newton CR. (2003)Severe P. falciparum malaria in Kenyan children: evidence for hypovolaemia. Qjm.; 96(6):427-434. doi: 10.1093/qjmed/hcg077.

[18] Das BS, Satpathy SK, Mohanty D, Mohanty S, Mishra SK, Satapathy PC, Patnaik JK, Bose TK.( 1988)Hypoglycaemia in severe falciparum malaria. Trans R Soc Trop Med Hyg.; 82(2):197-201. doi: 10.1016/0035-9203(88)90407-5. 
[19] Waruiru C, Pasvol G, Warrell D. et al.( 1993) Towards optimal regimens of parenteral quinine for young African children with cerebral malaria: the importance of unbound quinine concentration. Trans R Soc Trop Med Hyg.; 87(2):201-206. doi: 10.1016/0035-9203(93)90494-B.

[20] Dekker E, Hellerstein MK, Romijn JA, Neese RA, Peshu N, Endert E, Marsh K, Sauerwein HP. (1997)Glucose homeostasis in children with falciparum malaria: precursor supply limits gluconeogenesis and glucose production. J Clin Endocrinol Metab.; 82(8):2514-2521. doi: 10.1210/jc.82.8.2514. 